\title{
The smart city: challenges for the civil engineering sector
}

Ellie Cosgrave EngD

City Leadership Lab, Department of Science Technology Engineering and Public

Policy, University College London, London, UK (e.cosgrave@ud.ac.uk)

In the twenty-first century, engineers are being tasked with solving ever more complex and subtle societal challenges from climate change to unprecedented urbanisation that is materially affecting the lives of many urban populations. As engineers become ever more interdisciplinary and the boundaries of disciplines soften, they need to reflect as a community as to the appropriateness of the engineering paradigm to address these needs. Currently the engineering community is pointing to the digital technologies and the 'smart city' as a deliverer of efficiency and resilience without fully acknowledging the intricate sociopolitical context in which it is situated. This paper explores four key challenges that the (civil) engineering sector must contend with if it is to harness appropriately the potential of digital technologies while maintaining an ethical and productive foundation on which cities can thrive, including (a) embracing complexity, $(b)$ the smart city and social justice, $(c)$ financing the smart city and $(d)$ engineering education.

\section{Introduction}

It is clear from the literature and the variety of interpretations of a 'smart city' in urban strategies that it is a concept that is deeply contested (Caraglui and Del Bo, 2016; Hollands, 2008). However, the vision and drive towards an integration of digital technologies into the public infrastructure services has proven to be a compelling area of research and practice over the past 10 years. When people think of the smart city, it is easy to call to mind visions of sleek and seamless infrastructure: a well-oiled machine that performs so perfectly it becomes almost invisible. In this smart city, urban sensing predicts traffic hotspots, crime and pollution while actuators deal with it before a threat is even noticed. If that is the brief, the engineering sector will develop the technology to enable it. They can, and have, invented information and communication technology (ICT) to model and manage the city in real time; they have developed self-driving vehicles, and they will continue to innovate with 'smart technologies'. However, this vision also sits at odds with what is known of thriving cities, which depend not on order and control, but on the messiness of social processes, 'eyes on the street', creativity and serendipity (Jacobs, 1961). The agglomeration effect that cities offer thrives in part on disorder.

Inherent in the smart city are two conflicting truths. The first is that climate change and population growth mean that more efficient and effective ways must be found to meet the demands of citizens residing in cities. The second is that thriving cities require human connectedness, tension and disorder. Members of the engineering community are comfortable working within and delivering on the first challenge. Their training allows reducing a problem to its component parts and optimising for a known set of requirements. Their design tools and knowledge systems mean that they can be confident their designs are safe and will deliver required levels of efficiency.

However, the second challenge sits somewhat at odds with this reductionist engineering thinking. One cannot model the uncertainty or messiness of a city (although some have tried); one cannot 'optimise' for it to ensure that 'just the right amount' is acquired. The vibrancy of the city is instead a felt sense; it relates to belonging, connection, a sense of safety, of excitement and of possibility. Yet if the design brief for a new traffic interchange was 'a sense of possibility', the design team might be left scratching their heads. It is precisely this inability to respond to these design requirements that have led to harsh criticism of smart city developments such as Songdo and Mazdar, which, while being highly efficient, well operated and functional, are failing to attract communities to live there (Sennett, 2012).

This paper draws attention to the key challenges for the engineering community in coming to terms with the changing role and impact of ICT in cities. It does not aim to cover all of the challenges (of which there are many) but instead aims to highlight the areas that engineers are at most risk of not delivering on. They are the challenges that the author hopes to bring special attention to as ICT is continued to be incorporated into engineering design processes. As such, this paper focuses on the second 'truth' explained earlier: that the city is and must be treated as messy and uncertain.

This paper frames the smart city as a mechanism that affects social, political and economic outcomes and offers tangible examples of how this relationship plays out in practice. It provides an overview of the core elements of the smart city that must be brought to bear on city infrastructure planning projects and programmes as well as detailing the broader implications for the industry.

\section{Understanding the smart city}

While the smart city has been a topic of scholarly and commercial interest for the past decade, the concept has been diversely interpreted and, at times, co-opted for political and commercial purposes. The concept arose partly from the understanding that 
cities were becoming increasingly significant both politically and economically. Many papers and reports referring to the smart city begin with an acknowledgement that the driver of change is population growth, urbanisation and an opportunity to capitalise on the economic return possible through tech-based growth.

In 2016 an estimated 54\% of the global population lived in cities, with the figure expected to rise to $60 \%$ by 2030 (UN, 2016). Arup (2013) predicted that the global economy for the smart city will be $£ 408$ billion by 2020 . They also referenced the challenge of meeting the needs of such growth while vastly reducing carbon dioxide emissions and reliance on fossil fuels. The solution, or hope, is that more data, automation and control will allow decoupling growth from climate change by getting more from less: more mobility and energy from less infrastructure, more housing from less space, more construction from less time and more productivity from less resources.

The smart city has held the promise of optimisation, efficiency and control. The view has been that with more information, the city could be managed better, the 'everyware' of the city (as Greenfield (2006) dubs it) allowing society to carry on as normal, but 'better'. Traffic flow data can help in rerouting vehicles in real time and identify congestion hotspots so that longer-term planning is improved. Electric vehicles and smart energy meters can enable behaviour change around personal energy consumption while simultaneously reducing local pollution. Crime data can transform policing, citizen science can revolutionise research and virtual learning will transform education practices. Perhaps the greatest promise of all is that the smart city holds the possibility to integrate these systems effectively for the first time. By modelling the interrelationships between multiple city systems, the opportunities for efficiency multiply.

On top of this basic understanding that technology brings opportunities to improve city services, much of the smart city literature adds another layer. This literature is concerned with the knowledge economy, business models and innovation and governance principles that both drive the change towards smart technologies and emerge as a result of this transition. It explores the broader system of the smart city including, for example, how it is challenging traditional business models and making room for economic innovation and how it is transforming democratic participation and social mobility.

This literature set tries to incorporate and understanding of the social, political and economic implications of a move to the socalled everyware of the city (Greenfield, 2006). It asks in what ways should, for example, city governments be opening up the data that they hold and what should they be keeping private, Are new sharing city business models such as Uber and Airbnb changing city functioning? What is the role of the government in ensuring that this development is equitable and a positive change for the city? How can the government best support new local tech entrepreneurs in developing marketable smart city solutions?
These are questions whose answers evolve as technology (and the market) evolves, and as more time is spent investigating the complexity of the questions (Barns et al., 2017).

As Hollands (2008) argues, this view of a smart city holds that the technology itself is not sufficient to make a city 'smart'; instead, a smart city can emerge only in relation to people, processes and systems. Some cities have taken this a step further away from smart technology and claim that smart cities are simply about achieving the goals of the city. The Vienna Strategic Urban Plan, for example, is called 'Smart City Vienna', but makes no reference to ICT and is not a technology oriented plan. For Vienna, the smart city is one that 'conserves resources and the environment and improves its quality of living through innovation in all fields' (City of Vienna, 2016: p. 5).

However, as society struggles to come to an agreed definition of the smart city, it is possible to get distracted from the central purpose. Engineers, politicians, civil servants and academics argue that there is no need for a clear vision of how precisely future cities are expected to function. There is no need to prescribe a rigid end goal towards which society strives (Cosgrave et al., 2012). One thing that is certain is that the future is unknown, so prescribing an end goal is unhelpful as by the time that plans are achieved, the technology and the socio-economic context will have moved on.

Instead, the author calls for a smart city debate that centres on a deepening understanding of the ways in which ICT is currently transforming and challenging assumptions on how a city functions and is operated. This means a move away from the development of smart city indexes and benchmarking that compares which cities have the most investment in technology and a move towards a critical reflection on the changing role and potential of technology.

\subsection{The engineer and the smart city}

There are two main ways in which the narrative of the optimisable smart city is problematic in relation to engineering projects and programmes in cities. Firstly, the rhetoric of the smart city is somewhat distant from the day-to-day work involved in the production of engineering projects. Embedding broad and overarching challenges of digitisation into infrastructure design life cycles, project management and delivery is perceived as an extra (and costly) complication and a risk to successful completion. It is possible to argue that this is simply symptomatic of digital construction tools and models for urban-scale projects being in their relative infancy. As such, as technical capability and experience are developed (through e.g. the development and application of smart city standards and Building Information Modelling (BIM) level 3), these issues will naturally work themselves through.

Secondly, and perhaps more fundamentally, there is a clash in the notion of 'the city' itself. While on a theoretical and policy level 
it makes sense to conceptualise a city as a complex, wicked sociotechnical system, for engineers in practice looking to produce physical infrastructure, this framing is less useful. Engineering design is fundamentally built on a reductionist mode of thinking and requires clear design specifications (i.e. expected loads, efficiency requirements, design life etc.). This reductionism is also the mechanism by which engineers are currently legally held accountable through the application of design codes, and it ensures a regulated, safe and high-quality engineering sector.

This tension lies at the heart at of the current bifurcation of the smart city narrative. On the one hand, a technocratic interpretation is seen on how ICTs will transform city systems, and on the other hand, there exists the socio-economic narrative that explores urban innovation and entrepreneurialism, modes of citizen engagement and other socio-technical issues. Traditionally, the socio-technical analysis has critiqued the technical system analysis without engaging critically with why those paradigms have emerged.

If the engineering sector is to engage effectively with socio-economic concerns of the smart city that meet the needs of both citizens and policymakers while maintaining technical rigor, it is incumbent on both communities of experts to relate to one another's modes of thinking, rather than sitting at a dismissive distance.

The four challenges outlined in the following section lie at the interface of the social science understanding of the smart city and the technical interpretation. They are not necessarily the most immediate or pressing challenges for the engineering sector, but instead the ones that are at most risk of not adequately addressing. They are as follows

- embracing complexity

the smart city and social justice

- financing the smart city

- engineering education.

\section{Challenges for the engineering sector}

\subsection{Challenge 1: embracing complexity}

The engineering community must

- understand that 'smart infrastructure' serves social purposes

- be involved in these discussions pre-procurement.

As alluded to in the previous section, a key challenge for the engineering community is to understand the distinct ways in which engineering, and particularly digital infrastructure, is related to and affects social, political and economic processes (Tilson et al., 2010; Vaast and Walsham, 2009). As Barns et al. (2017: p. 21) note, these include 'include the changing industry, regulatory, and market structures as well as the wide-ranging effects on citizens' lives, work, and interactions that have been rapidly advanced the most recent wave of digitization'. This work is founded in complex systems theory which characterises the city as inherently messy or 'wicked' (Batty, 2010). Contrary to this, however, much of the smart city collateral produced by engineering firms conceives the city instead as a complicated machine that can be optimised and solved. In their vision paper Innovation 2050: a Digital Future for the Infrastructure Industry, Balfour Beatty (2017: p. 4) claims that 'adopting and mainstreaming digital and other new technologies, such as advances in robotics and artificial intelligence, will be a gamechanger for the industry, speeding up the otherwise slow-andsteady modernisation of the sector, and providing answers to the challenges and opportunities we face'.

Similarly, Bechtel (2018) presents a vision of a digitally optimised city (Figure 1). Here the smart city is reduced to its component infrastructure services, each of which can be optimised or improved, with an implicit suggestion that the city as a whole may be optimised.

It is possible to interpret the smart city as simply improving infrastructure provision through construction management processes with the use of BIM and digitisation of design and delivery, or improving building life cycle management. Many companies can and do market their smart city capability by segmenting their offer. Some models deliver a reductionist 'smart city as an operating system' model - which assumes that the whole city can be managed and optimised, if only the data existed. A key opportunity cost of pursuing this view of the smart city is that vendors look to find opportunities to sell their existing products and services to city governments, rather than addressing the complex and multiple needs of cities. It is known, for example, that following the theory of induced demand (Litman, 2001), when the capacity of infrastructure systems is increased, more demand is created for them, rather than solving problems of congestion. It is possible that smart city solutions that seek only to improve capacity and efficiency rather than radically challenging usage norms could simply be compounding the problem of resource overuse.

A key challenge to the industry is to understand how much to optimise current systems and how much to invest in developing truly transformative approaches to city service delivery that stretch beyond existing paradigms.

While, of course, technical excellence and innovative design is imperative to creating healthy and functional cities, conceptualising the city only in this way is problematic. These visions of the smart city do not offer the opportunity or space to reimagine infrastructure systems or think beyond the individual project to understand the bigger picture of how infrastructure programmes are conceived in the first place, the actors that lobby for a certain type of investment, the new business models such as Airbnb and Uber that are reshaping demand or the role of new financing models and policies. The author welcomes a smart city that shifts and challenges resource use paradigms rather than reinforcing them. 


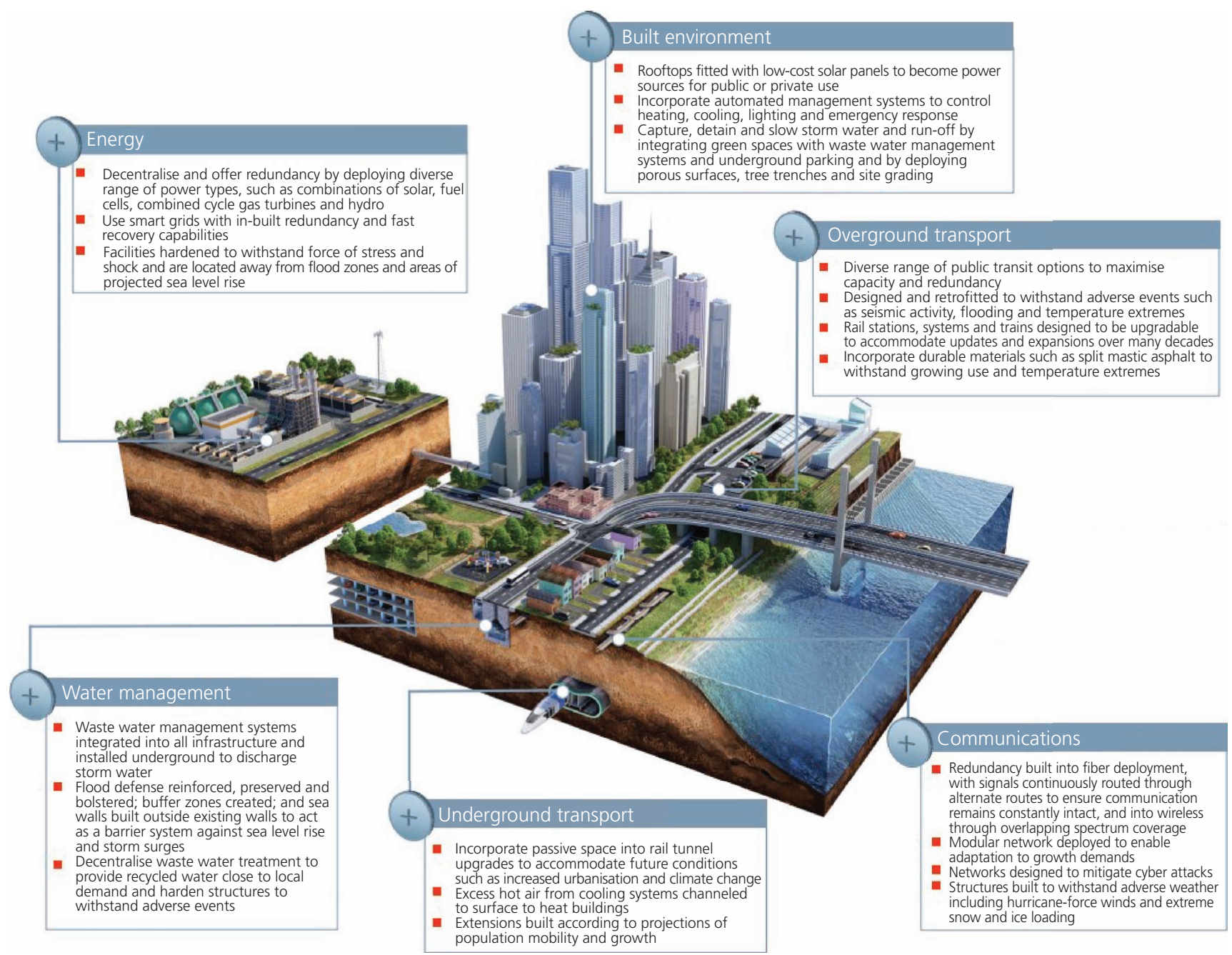

Figure 1. Bechtel's (2018) view of the smart city

\subsubsection{Rio centre of operations}

The centre of operations in Rio has come under some scrutiny as an exemplar of the reductive and commercially driven smart city ideology described earlier. Morozov (2013), for example, points to a technological 'solutionism' whereby ICT is pushing solutiondriven rather than problem-driven technologies.

The centre of operations was created out of a strong political drive from the mayor. It was originally in the Olympic plan for 2016 and was accelerated due to a desire to modernise the city's emergency response capability. The city had suffered severe loss of life after the 2010 landslides and wanted to improve its response capacity. The centre of operations was built from scratch in 8 months in partnership with IBM and Oracle and is used by decision makers in the city to operate general city services, particularly to coordinate emergency response (Kitchin, 2014).

Over time, the administration began to develop routine operational uses for the centre of operations. For example, the garbage trucks are coordinated through the Global Positioning System so that in an emergency trucks can be repurposed for other tasks. This helps the city manage resources while simultaneously improving responses to disasters.

Many people have criticised the Rio control room as being exactly the reductionist, command and control ideology, with the government responding to market push from IBM and Oracle, rather than a true need. Rodrigo Rosa, the then advisor to the mayor claimed instead that

[t]his is more than just the screens in the situation room; it's a significant organisational shift and degree of professionalism for us. It's actually a whole change of mind-set in terms of how you plan and how you deal with public management in general. (BIS, 2013: p. 15)

The city's media outlets also have a seat in the control room, signifying in principle and practice that this initiative is open, transparent and 'for the people'. 
The story of the control room is therefore both social and technological. It exemplifies that two apparently similar looking technology solutions can serve very different purposes. When the infrastructure is designed with a clear view on what it means for the city authority's organisational progress, it has the opportunity to become truly embedded into the city's processes. This is not to say that the centre of operations was a clear example of a smart city solution working perfectly. There were many concerns from citizens that this was simply a mechanism to spy on citizens better and that they are investing only because they want to showcase Rio on the world stage for the World Cup and Olympics.

\subsection{Challenge 2: the smart city and social justice}

The engineering community must

- develop the capability to comment on and address the economic and social consequences of technology innovation

- take steps to improve the diversity of the profession.

Advances in technology and new tech-oriented businesses models have implications for social equality. Urban infrastructures, whether physical or digital, reproduce existing discrimination, despite the rhetoric of valuing inclusivity (Graham and Marvin, 2001). This plays out not only in terms of unequal access to the technology within and between cities (the digital divide) but also due to its tendency (if unchecked) to magnify existing social inequalities. This is particularly relevant in a neo-liberal context where private rather than public interests are protected, the smart city creates the market for increasing existing social divides, particularly with respect to wealth and gender and racial inequalities. A recent conference at the Institution of Civil Engineers focused on revealing the ways in which infrastructure systems are inclusive of the diverse needs of urban populations. Here, the institution argued 'to drive truly inclusive design, break from traditional approaches and not repeat what's already been done, a total shift in the paradigm on how cities are designed and managed is needed' (ICE, 2018: p. 2). It is possible for digital technologies to be part of this transformation if designers are cognisant of the ways in which these technologies are inclusive and potentially divisive.

\subsubsection{Wealth divide}

\subsubsection{ACCESS TO TECHNOLOGY (DIGITAL DIVIDE) WITHIN AND BETWEEN CITIES}

When constructing the smart city, it is important to understand for whom these technologies are being developed. Who are the ultimate beneficiaries and who may be left behind? There is a vast body of literature that explores the notion of the digital divide, which describes the proliferation of the Internet and data as an uneven, multidimensional phenomenon (Calzada and Cobo, 2015). Simplistically one could focus simply on levels of access to the Internet. For example, in 2016, 10\% of adults in the UK had never used the Internet. When the data for specific groups are looked into, it is found that $61 \%$ of those over 75 and $25 \%$ of disabled adults had never used the Internet. Looking globally at the same year, only $46 \cdot 1 \%$ of people have access to the Internet. It is incumbent on the engineering sector, therefore, to question critically the accessibility of the technology that they design and deliver.

There is currently no adequate mainstream forum for engineering companies to develop the knowledge, skills and business models required to challenge effectively the social impact of their designs. The author calls for an engineering sector that is more politically engaged and able to challenge the assumptions and demands of their clients as well as governments and regulating authorities.

Even when an individual has access to the technology, a range of social factors may limit their ability to seek equal advantage from it, suggesting significant socio-technical misalignment (Rifkin, 2000; Selwyn, 2004). This form of digital divide is elaborated further in this paper.

\subsubsection{LABOUR AGAINST CAPITAL PLATFORMS AND EMPLOYMENT RIGHTS}

Entrepreneurs capitalising on the platform and service economy have allowed for an explosive and unprecedented rate of global expansion of both labour- and capital-based businesses. In less than 5 years, Uber was able to roll out its mobility service in over 300 cities and was facilitating over a million journeys worldwide per day (Freier, 2015). Meanwhile Airbnb became active in nearly every country in the world and accommodates over half a million stays per night (Smith, 2017). However, this global expansion has been met with much criticism over employment rights such as adherence to the local minimum wage, pensions and paid leave. While Uber and other platform-based services battle these issues out in the courts, there is a broader concern emerging around whether these platforms are widening the gap between the rich and poor.

A JPMorgan study made a comparison between an individual's monthly earnings from labour against capital platforms (see Figure 2). They found that those who are using labour platforms tend to use them to top up shortfalls in monthly earnings and as such see no increase in wealth from using them; they merely support them in maintaining a stable income. In contrast, those using capital platforms (such as Airbnb) use the platform to increase their monthly earnings. Note also that the people using these capital platforms are not only more asset-rich than their labour counterparts, but they also earn on average $\$ 1000$ per month more. This is a clear example of how what at first appears to be exciting and socially benign technical innovation can have a skewed and divisive socio-economic impact.

\subsubsection{Gender divide}

\subsubsection{WHO ARE SMART CITY SOLUTIONS OPTIMISING THE CITY FOR?}

Similarly, when the narrative of the smart city is to optimise travel in the city services, it must be understood that from a user perspective, optimisation has multiple interpretations. For example, the optimal mode of transport for an able-bodied young professional will vary significantly from that of an elderly person 


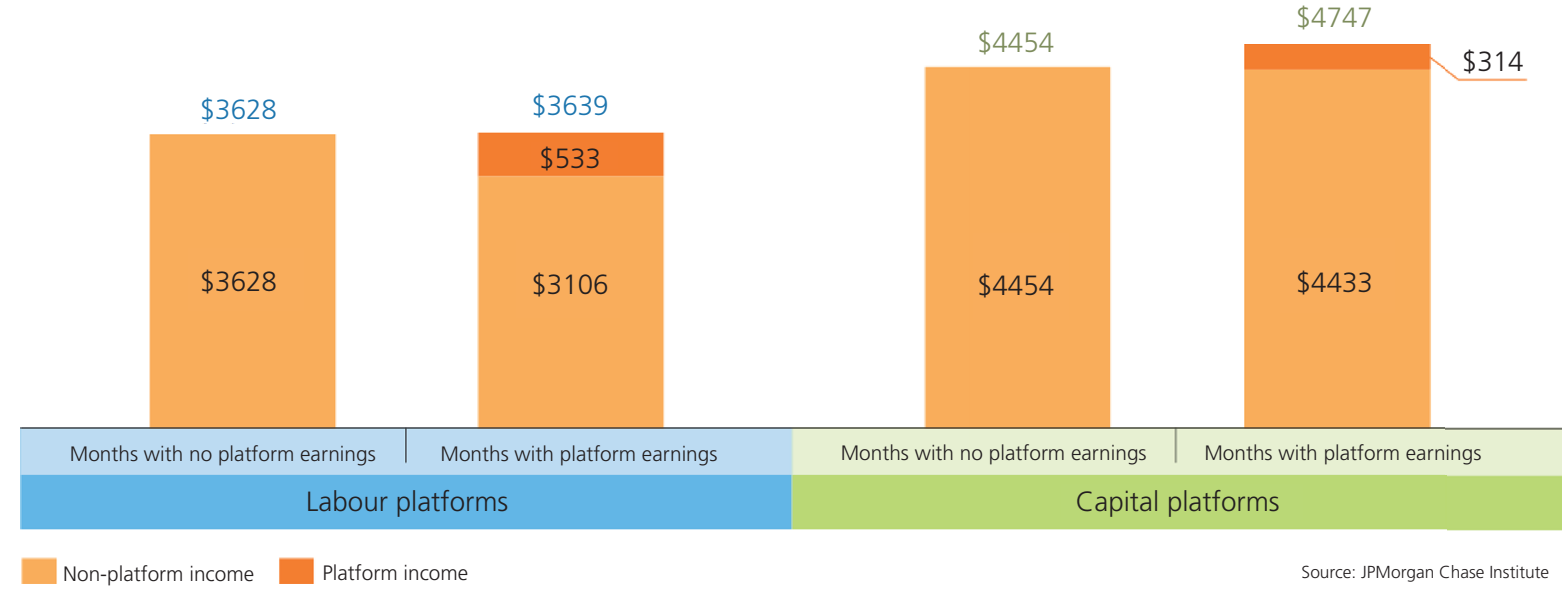

Figure 2. Earning in months with and without platform earnings (reference: JP Morgan study)

with caring responsibilities. As such, assumptions that enter design criteria must be critically evaluated to ensure that they are not designed only for one section of the population.

Traditionally, for example, transport planning reflects an implicit androcentric bias since it has prioritised journeys enabling participation in the formal labour market, from which women were historically excluded and continue to face barriers to advancement (Law, 1999). The eminence of the journey to work also reinforces the utilitarian conceptualisation of transportation as purely functional and efficient while neglecting leisure- and care-related journeys (Whitzman, 2005: p. 37). Women tend to make more frequent, short-distance, encumbered journeys than men do, entailing household and care responsibilities, while men tend to make less frequent longer distance journeys (Levy, 2013: p. 55). As such, public transportation is unevenly distributed and gendered because it privileges radial, long-distance journeys as opposed to orbital, short-distance ones (Levy, 2013). The failure of engineering to account for gender inequalities in urban mobility is detrimental to women's personal and professional development, economic status, leisure time and overall well-being.

When digitisation (or 'smartening') of transport is placed on top of the existing system, it magnifies this divide. For example, a common critique of Citymapper is that it does not allow for the diversity of user needs. There is no distinction, for example, between routes offered that are cognisant of women's safety needs or routes that are 'buggy friendly'. As such, the existing transport infrastructure gender gap is compounded when digital infrastructure solutions fail to incorporate multiple experiences of the city.

\subsubsection{TECH ENTREPRENEURS}

The historic legacy of male dominance in engineering knowledge production and professional practice coupled with the present reality that in the UK $91 \%$ of engineering professionals are male (Institution of Engineering and Technology, 2015) means that it is unlikely that the female experience is adequately incorporated into engineering problem structuring and decision-making. This implies that engineering practice is unable to account for the diversity of the populations that it is intended to serve. Much of the smart city rhetoric is influenced not just by the engineers but also by the community of tech entrepreneurs, which compounds this problem.

The philosophy that the smart city is an entrepreneurial city and that this market of young innovators will be able to solve social problems through neo-liberal small and medium-sized enterprises (SMEs) is an issue when who comprises this community are considered. A CB Insights (2010) study found that $87 \%$ of venture-capital-backed companies are headed by a white person and those headed by a male received $98 \%$ of investment in the USA. That investment represents $\$ 1.88$ billion received by male executives as opposed to $\$ 32 \cdot 2$ million in funding for the females. If that is who is inventing the technology, then that is who the technology represents and serves (CB Insights, 2010). When women, or any group, are excluded from the discussion, they are excluded from the solution.

While technology allows opportunities for positive futures, it also allows for increased security issues. In 2012, the app Girls around Me was developed to support men in stalking, or 'hunting down' women. It scrapes data from social media platforms such as Foursquare and Facebook, allowing users to see pictures of women and their location and even message them (Ashburn, 2012). This is an example of how an entrepreneurial smart technology can increase the vulnerability of certain groups to crime. Technology infrastructure developers need to engage with these issues and collaborate with policymakers to develop real solutions - which may be tech or policy based.

Dominance functions by remaining invisible and unexamined. Central to any feminist analysis is making implicit assumptions explicit, highlighting how they reinforce power dynamics and challenging them in order to achieve more equitable and socially just outcomes. Since the built environment and its form and functions are 
the result of someone's conscious intention, infrastructure reflects, reinforces and reproduces gender and other such power inequalities in society (Ehrnberger et al., 2012: p. 85). Given the ability of smart technologies to magnify existing social inequality, engineering has a significant challenge to make assumptions explicit and safeguard against the vulnerability it perpetuates.

\subsection{Challenge 3: financing the smart city}

- The smart city does not have to be a new line on the city authority's budget.

- There is a need for new partnerships and business models.

As city budgets in the UK are increasingly reduced and with basic public services being cut back or entirely shut down, a critical question arises around how cities can justify expenditure towards 'futuristic' smart city solutions. Many UK government tech incubation agencies have been criticised by local authorities for being too disjointed from the day-to-day needs of public service. It is the role of technologists and policymakers to work together to create mechanisms that will allow them to incubate technologies that are affordable and implementable to meet today's needs as well as future ones. The soon-to-be-founded London Office of Technology and Innovation will seek to meet this policy need and link the intelligence work of the Greater London Authority more closely with the authorities.

Of course, the answer is not straightforward. With shrinking budgets, complex decisions have to be made about the balance between technology upgrades, futures investments and delivering on frontline needs. These decisions are often political, but the engineering sector must develop a capability to understand the real social and economic contribution of their systems so that they may enter into more nuanced policy conversations with public sector investors.

There is, however, another approach to making the case for improving tech expenditure in cities, which is to look at the efficacy of current ICT investment. By analysing the budgets of local authorities, it is possible to gain some understanding of the ICT-related expenditure of the public sector. In their Delivering the Smart City study, Cosgrave et al. (2014) analysed the spending patterns of eight UK cities over a 3-year period. Across the city council, they searched for either expenditure marked as ICT or expenditure with firms that are known to have ICT as their main service offering is ICT.

The results showed that on average, $6 \%$ of the local authority's budget was spent on ICT services, with some councils such as Coventry, Bristol and Liverpool spending nearly $10 \%$. This is comparable to the financial service sector, which spends $8 \%$ of their budgets on ICT and is known to have very sophisticated ICT systems (Guevara et al., 2013). The implication is that if city authorities are already spending a significant percentage of their budgets on ICT, there is an opportunity to repurpose it in a way that supports better results in a way that supports the local economic development.
The same study found that $98 \%$ of local authority spend on ICT is with large multinational ICT companies. This sits in contrast to many areas of smart city investment which is trying to encourage innovation and creative solutions from local SMEs and entrepreneurs. While many parts of the authority seek to de-risk ICT investment through working with large multinationals, it does not support the development of innovative solutions and investment in the local economy. There must be policies and mechanisms which could support this picture in becoming more balanced.

\subsection{Challenge 4: engineering education}

This challenge involves

- the need for training in critical thinking and its role in global urban challenges

- recruitment of engineers

- development of digital skills.

\subsubsection{Teaching the social role of engineering: problem- based learning}

Many universities across the UK are beginning to understand that training their students in critical thinking and supporting them in developing an understanding of their role in global urban challenges is a core part of their engineering education. However, the predominant teaching paradigm of 'chalk and talk' reminiscent of 1950s-style education remains a central mode of teaching. As a practical and design-oriented profession, this teaching mode has been critiqued as insufficient in moulding graduates who are able to compete with the complex demands of a rapidly changing workplace, human relations and social impact (Mills and Treagust, 2003).

In response to (relatively) new engineering challenges such as climate change, sustainability and development, many universities are employing problem-based learning (PBL) approaches. For example, at the School of Mechanical and Systems Engineering at Newcastle University, PBL is used to support the students in gaining an understanding of the complexity of sustainability issues in their design (Joyce et al., 2013).

While this is happening at a small scale in universities across the $\mathrm{UK}$, an interesting new model of engineering education is emerging where external organisations are offering courses for university students that help them grapple with these challenges in a competitive environment. For example, Engineers without Borders UK (EWB-UK, 2017) offer the 'Engineering for People Design Challenge' to thousands of undergraduate students every year. For this challenge, EWB-UK developed a real-life social challenge for the students to develop an engineering solution and compete with students from other universities to win the prize. This type of education supports students in developing a more holistic understanding of the capabilities of engineering to meet complex social issues.

These types of challenges also support students in working with expertise beyond their traditional disciplines. At University College 
London, the How to Change the World undergraduate module gets students from the different engineering departments (including mechanical, chemical, civil and biomedical engineers; computer scientists; and students from the management school) to work together on a single problem (UCL Steapp, 2017). During the two intensive weeks, students gain an appreciation as to how different perspectives can come together to meet global challenges. As society moves towards the smart city, engineers will work increasingly with computer scientists, economists and environmentalists, as such it is imperative that the education provided to students equips them appropriately. Engineers should be equipped to work with people from other domains to deliver integrated smart city solutions, rather than considering engineering as the sole producer of the smart city. Engineering education will play a key role in developing the capabilities of engineers to interact with expertise beyond their discipline, including the social and political sciences. Therefore, collaboration with community groups, non-governmental organisations and policymakers in PBL programmes is essential. The Stanford Human Cities programme, for example, adopts an interdisciplinary curriculum in their urban studies teaching, drawing on the disciplines of 'engineering, social sciences, and design thinking, with a focus on experiential learning through empathetic and ethical fieldwork' (Human Cities Initiative, 2018).

\section{Conclusion}

In order to be able to contribute to smart infrastructure and construction that serve social as well as technical requirements, engineers must be able to engage in critical debates that incorporate and value human experience. This requires them to challenge educational institutions and knowledge systems. It asks them to dig deep into the wealth, gender, class, race, sexuality, age and disability divides that they might be widening. New business models and partnerships must be developed that can ensure that the best design is affordable in times of a reducing public purse. They must develop a language and a knowledge system that is complementary to local, national and international policies, so that technical knowledge may better inform political decision-making.

It is particularly incumbent on today's engineering community to challenge modes of thinking which are rooted in historic understanding of how engineering decisions should be made and of the society that they intend to serve. Smart technologies hold an opportunity to challenge modes of design. As engineers explore this, they should not miss the opportunity to create an urban infrastructure system that serves all urban dwellers.

\section{REFERENCES}

Arup (2013) The Smart City Market: Opportunities for the UK. UK Department for Business, Innovation and Skills, London, UK, research paper no. 136

Ashburn L (2012) Girls gone wrong: new stalking app needs to go. Huffington Post, 2 April. See http://www.huffingtonpost.com/laurenashburn/girls-around-me-app_b_1396702.html (accessed 29/05/2017).

Balfour Beatty (2017) Innovation 2050: a Digital Future for the Infrastructure Industry. Balfour Beatty, London, UK.
Barns S, Cosgrave E, Acuto M and Mcneill D (2017) Digital infrastructures and urban governance. Urban Policy and Research 35(1): 20-31, http://dx.doi.org/10.1080/08111146.2016.1235032.

Batty M (2010) Complexity of city systems: understanding, evolution and design. A Planner's Encounter with Complexity, 1st edn. (DeRoo G and Silva E (eds)) Routledge, New York, NY, USA.

Bechtel (2018) How to Transform Your City with Smart, Resilient Infrastructure. Bechtel, San Francisco, CA, USA.

BIS (UK Department for Business, Innovation and Skills) (2013) Smart Cities International Case Studies: Global Innovators. BIS, London, UK. See https://www.gov.uk/government/publications/smart-citiesinternational-case-studies-global-innovators (accessed 29/05/2017).

Calzada I and Cobo C (2015) Unplugging: deconstructing the smart city. Journal of Urban Technology 22(1): 23-43, http://dx.doi.org/10.1080/ 10630732.2014 .971535$.

Caraglui A and Del Bo C (2016) Do smart cities invest in smarter policies? learning from the past, planning for the future. Social Science Computer Review 34(6): 657-672, http://dx.doi.org/10.1177/ 0894439315610843.

CB Insights (2010) Venture Capital Human Capital Report-Gender, Race, Age, Education Demographics on VC Backed Company Founders. CB Insights, New York, NY, USA.

City of Vienna (2016) Smart City Wien - Framework Strategy, 2nd edn. City of Vienna Administration, Vienna, Austria.

Cosgrave E, Tryfonas T and Cater K (2012) Developing an ICT-enabled, anti-prophetic approach to sustainable cities. In 2012 7th International Conference on System of Systems Engineering (SOSE). Institute of Electrical and Electronics Engineers, Piscataway, NJ, USA, pp. $47-52$.

Cosgrave E, Doody L, Walt N and Buscher V (2014) Delivering the Smart City, Governing Cities in the Digital Age. Arup, London, UK. See $\mathrm{http}: / /$ publications.arup.com/publications/d/delivering the smart city (accessed 29/05/2017).

Ehrnberger K, Rasanen M and Ilstedt S (2012) Visualising gender norms in design: meet the Mega Hurricane Mixer and the drill Dolphia. International Journal of Design 6(3): 85-98.

EWB-UK (Engineers without Borders UK) (2017) Engineering for People Design Challenge. EWB-UK, London, UK. See https://www.ewb-uk. org/engineering-for-people/ (accessed 29 /05/2017).

Freier A (2015) Uber Usage Statistics and Revenue. Business of Apps, Staines-upon-Thames, UK. See http://www.businessofapps.com/uberusage-statistics-and-revenue/ (accessed 29/05/2017).

Graham S and Marvin S (2001) Splintering Urbanism: Networked Infrastructures, Technological Mobilities and the Urban Condition. Psychology Press, Hove, UK.

Greenfield A (2006) Everyware: the Dawning Age of Ubiquitous Computing. New Riders Boston, MA, USA.

Guevara J, Hall L and Stegman E (2013) IT Key Metrics Data 2013: Index of Published Documents and Metrics. Gartner Inc., Stamford, CT, USA.

Hollands RG (2008) Will the real smart city please stand up? City 12(3): 303-320, http://dx.doi.org/10.1080/13604810802479126.

Human Cities Initiative (2018) About Human Cities. Human Cities Initiative, Stanford University, Stanford, CA, USA. See http://www. humancities.org/about (accessed 24/03/2018).

ICE (Institution of Civil Engineers) (2018) What Is the City but the People? The Role of the Engineer in Creating Inclusive Cities. ICE, London, UK. See https://www.ice.org.uk/inclusivecities (accessed 24/03/2018).

Institution of Engineering and Technology (2015) Skills and Demand in Industry, 2015 Survey. Institution of Engineering and Technology, Stevenage, UK. See http://www.theiet.org/factfiles/education/ skills2015-page.cfm (accessed 24/03/2018).

Jacobs J (1961) The Death and Life of Great American Cities. Random House, New York, NY, USA.

Joyce T, Evans I, Pallan W and Hopkins C (2013) A hands-on project-based mechanical engineering design module focusing on sustainability. 
Smart Infrastructure and Construction

Volume 170 Issue SC4
The smart city: challenges for the civil

engineering sector

Cosgrave
Engineering Education 8(1): 65-80, http://dx.doi.org/10.11120/ened. 2013.00008 .

Kitchin R (2014) The real-time city? Big data and smart urbanism. GeoJournal 79(1): 1-14, http://dx.doi.org/10.1007/s10708-013-9516-8.

Law R (1999) Beyond 'women and transport': towards new geographies of gender and daily mobility. Progress in Human Geography 23(4): 567-588, http://dx.doi.org/10.1191/030913299666161864.

Levy C (2013) Travel choice reframed: 'deep distribution' and gender in urban transport. Environment and Urbanization 25(1): 47-63, http:// dx.doi.org/10.1177/0956247813477810.

Litman T (2001) Generated traffic: implications for transport planning. ITE Journal 71(4): 38-47.

Mills J and Treagust D (2003) Engineering education - is problem based or project based learning the answer? Australian Journal of Engineering Education 3(2): 2-16.

Morozov E (2013) To Save Everything, Click Here: Technology, Solutionism, and the Urge to Fix Problems That Don't Exist. Allen Lane, New York, NY, USA.

Rifkin J (2000) The Age of Access: the New Culture of Hypercapitalism, Where All of Life is a Paid-for Experience. J.P. Tarcher/Putnam, New York, NY, USA.

Selwyn N (2004) Reconsidering political and popular understanding of the digital divide. New Media \& Society 6(3): 341-362, http://dx.doi.org/ $10.1177 / 1461444804042519$
Sennett R (2012) No one likes a city that's too smart. The Guardian, 4 December. See http://www.guardian.co.uk/commentisfree/2012/dec/ 04/smart-city-rio-songdo-masdar (accessed 03/05/2018).

Smith C (2017) AirBnB Statistics. DMR Stats. See http:// expandedramblings.com/index.php/airbnb-statistics/ (accessed 29/05/ 2017).

Tilson D, Lyytinen K and Sørensen C (2010) Research commentary digital infrastructures: the missing is research agenda. Information Systems Research 21(4): 748-759, http://dx.doi.org/10.1287/isre.1100. 0318.

UCL Steapp (University College London Department of Science, Technology, Engineering and Public Policy) (2017) How to Change the World. UCL Steapp, London, UK. See http://www.ucl.ac.uk/ steapp/how-to-change-the-world (accessed 29/05/2017).

UN (2016) The World's Cities in 2016 Data Booklet. UN, New York, NY, USA.

Vaast E and Walsham G (2009) Trans-situated learning: supporting a network of practice with an information infrastructure. Information Systems Research 20(4): 547-564, http://dx.doi.org/10.1287/isre.1080. 0228 .

Whitzman C (2005) Women's safety and everyday mobility. In Building Inclusive Cities: Women's Safety and the Right to the City (Whitzman C, Legacy C, Andrew C et al. (eds)). Routledge, New York, NY, USA, pp. 35-52.

\section{How can you contribute?}

To discuss this paper, please email up to 500 words to the editor at journals@ice.org.uk. Your contribution will be forwarded to the author(s) for a reply and, if considered appropriate by the editorial board, it will be published as discussion in a future issue of the journal.

Proceedings journals rely entirely on contributions from the civil engineering profession (and allied disciplines). Information about how to submit your paper online is available at www.icevirtuallibrary.com/page/authors, where you will also find detailed author guidelines. 